\title{
Synchrotron FT-IR microspectroscopic analysis of necrotic bone
}

\author{
Sevgi Haman Bayarı ${ }^{\mathrm{a}, *}$, Haluk Utku $^{\mathrm{b}}$, Yuka Ikemoto ${ }^{\mathrm{c}}$, Bülent Celasun ${ }^{\mathrm{d}}$, Mahmut Kömürcü ${ }^{\mathrm{e}}$ \\ and Aziz Atik ${ }^{\mathrm{e}}$ \\ ${ }^{a}$ Hacettepe University, Faculty of Education, Department of Physics Education, Beytepe 06800, \\ Ankara, Turkey \\ ${ }^{\mathrm{b}}$ Institute of Nuclear Sciences, Hacettepe University, Beytepe 06800, Ankara, Turkey \\ ${ }^{\mathrm{c}}$ JASRI/SPring-8, Kouto, Sayo, Hyogo 679-5198, Japan \\ d Baskent University, School of Medicine, Department of Pathology, Bahcelievler 06490, \\ Ankara, Turkey \\ ${ }^{\mathrm{e}}$ Gulhane Medical Academy, Department of Orthopedic, Etlik 06018, Ankara, Turkey
}

\begin{abstract}
Avascular necrosis (osteonecrosis) is a disease that results from the temporary or permanent loss of blood supply to the bone. Synchrotron FT-IR microspectroscopy has been used to study the changes in mineral and matrix content of necrotic bone. FT-IR spectroscopic analysis revealed that in necrotic bone the relative mineral/matrix ratio decreased. Spectroscopic differences were observed between normal and necrotic bones. The noticeable differences may have important implications for analyzing and evaluating death bone.
\end{abstract}

Keywords: Avascular necrosis, necrotic bone, synchrotron, FT-IR microspectroscopy

\section{Introduction}

Avascular necrosis (also called osteonecrosis, aseptic necrosis, or ischemic bone necrosis) is a disease that results from the temporary or permanent loss of blood supply to the bone. When blood supply is cut off, tiny breaks within the bone occurs, the bone tissue dies and the bone collapses. If avascular necrosis occurs near a joint, collapse of the joint surface may occur.

Avascular necrosis may occur in any bone, but most commonly occurs in the ends (epiphysis) of long bones such as the femur. It may affect one bone, several bones at one time, or different bones at different times. Avascular necrosis may affect both genders and all age groups. The exact mechanism of this process is poorly understood, the most common etiologic event is trauma [1]. The symptoms of avascular necrosis may resemble other medical conditions or bone problems. In addition to a complete medical history and physical examination, diagnostic procedures for avascular necrosis may include $\mathrm{X}$-ray, computed tomography scan, magnetic resonance imaging, radionuclide bone scan and biopsy.

A considerable advantage of vibrational microscopy and imaging, somewhat overlooked in biomedical applications, is direct access to molecular structure information. IR spectroscopy, microspectroscopy, infrared imaging of bone have been used extensively to examine protein content, phosphate and carbonate

\footnotetext{
${ }^{*}$ Corresponding author: Sevgi Haman Bayar1, Hacettepe University, Faculty of Education, Department of Physics Education, Beytepe 06800, Ankara, Turkey. Tel.: +90 31229786 06; Fax: +90 31229786 00; E-mail: bayari@ hacettepe.edu.tr
} 
content and environment, and mineral crystallinity [2-9]. The use of synchrotron IR beam for microspectroscopy offers the great advantage of 100-1000 times greater brightness, compared to the IR beam of a globar source. Synchrotron radiation-based FT-IR microspectroscopy is proving an invaluable technique that provides ultra spatially resolved spectroscopic information and a higher signal-to-noise ratio on minute quantities of microscopic structures within a given sample [10].

There is no investigation about molecular structure of necrotic bone has been reported in the literature. Therefore, in the current study, we made use of synchrotron infrared microspectroscopy (at the SPring-8) to investigate the molecular changes associated with the avascular necrosis.

\section{Material and methods}

\subsection{Preparation of bone samples}

Biopsies from two groups of subjects, necrotic and normal (healthy) were supplied by orthopedic department of the GATA hospital. Paraffin embedding samples were prepared by the pathology departments at the Başkent University. Five-micron-thick tissue sections were cut from paraffin embedded biopsies. Sections were fixed on $\mathrm{ZnSe}$ slides, suitable for infrared transmission analysis. Two paraffin sections were cut from each case; one was placed on $\mathrm{ZnSe}$ slide for infrared transmission analysis, and the other on glass slide for light microscope.

\subsection{Synchrotron FT-IR microspectroscopy}

The infrared spectra in the $4000-720 \mathrm{~cm}^{-1}$ range were collected by an FT-IR (Bruker 120HR/X) and IR microscope system equipped with liquid nitrogen cooled mercury cadmium telluride detector using a synchrotron-radiation source at BL43IR of SPring-8. Synchrotron FT-IR maps with a FWHM $10 \mu \mathrm{m}$ beam size appear to provide a better spatial resolution capable of discerning single nuclei in the tissue matrix. The microscope was equipped with an automatic $x, y$ stage. A screen image recorder camera attached to the microscope enabled the acquisition of a photomicrograph of the investigated area. For each spectrum, 64 spectra with a resolution of $4 \mathrm{~cm}^{-1}$ are collected and averaged. The beam size at the focus point of the microscope is $10 \mu \mathrm{m}$ diameter without using aperture. Step size between each point was $10 \mu \mathrm{m}$ in both $x$ and $y$ direction. Before capturing the IR image, the ZnSe window is measured as a reference, and a background spectrum was collected.

\subsection{Data analysis}

The phosphate $\nu_{1}, \nu_{3}$ band $\left(900-1200 \mathrm{~cm}^{-1}\right.$ region) and the Amide I band $\left(1590-1720 \mathrm{~cm}^{-1}\right)$ were separately baselined. Mineral-to-matrix ratio was calculated by integrating the area under the peaks at 900-1200 $\mathrm{cm}^{-1}\left(\nu_{1}, \nu_{3}\right.$ phosphate $\left.\mathrm{PO}_{4}{ }^{3-}\right)$ and $1590-1720 \mathrm{~cm}^{-1}$ (Amide I) following subtraction of the contribution from paraffin. The relative carbonate content was calculated from IR spectra by taking the ratio of the integrated area of the $\nu_{2} \mathrm{CO}_{3}{ }^{2-}$ band $\left(850-890 \mathrm{~cm}^{-1}\right)$ and of the $\nu_{1}, \nu_{3}$ phosphate $\mathrm{PO}_{4}{ }^{3-}$ stretching band. Baseline correction, integrated peak areas were calculated using OPUS 5.0 program(Bruker). The color coded images of the mineral-to-matrix ratio and carbonate-to-phosphate ratio were constructed using CYTOSPEC IR imaging demo software (www.cytospec.com) with red indicating the strongest absorbance and blue the lowest. 


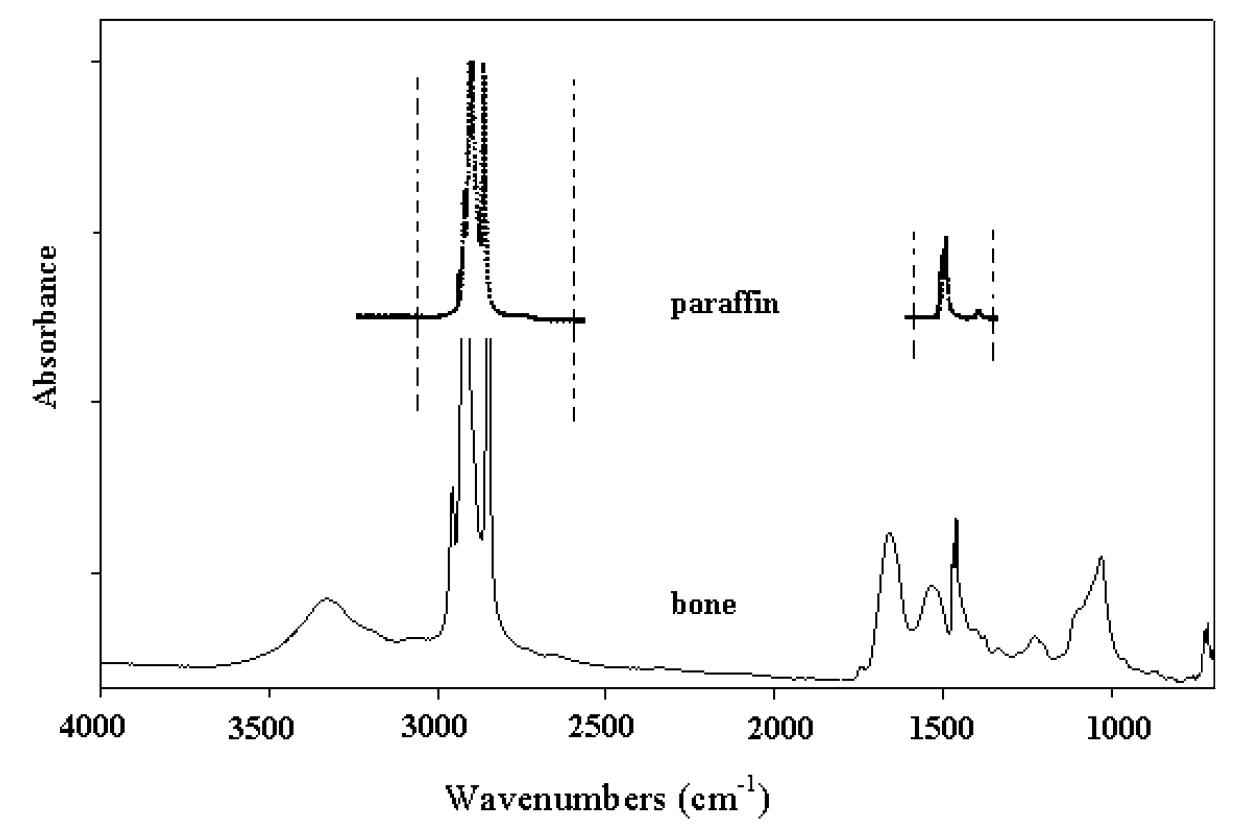

Fig. 1. Comparison of the infrared spectra of paraffin (dotted line) and paraffinized bone (full line).

\section{Result and discussions}

\subsection{Bone structure and infrared spectra}

Bone consists primarily of mineral and an extra cellular matrix (predominately type I collagen) [11]. The protein and mineral constituents produce intense, structure-sensitive IR bands. An infrared spectrum of normal bone is a fingerprint that reflects its composition. First, we compared an average infrared absorption spectrum recorded on a thin section of a paraffinized normal bone with that of paraffin (Fig. 1).

The method of choice for preparing thin sections of biological tissue is cryogenic sectioning with a microtome. However, cryo-sectioning is often not possible. In these cases, thin samples are often prepared by embedding the sample in a matrix and then cutting with a microtome. Paraffin is often used to embed unmineralized biological tissues because its most intense absorbance features are limited [12]. As can be seen from Fig. 1, C-H stretching vibrations of paraffin appears between 3000 and $2800 \mathrm{~cm}^{-1}$. Paraffin also contributes to the bands at 1460 and $1380 \mathrm{~cm}^{-1}$ as a result of $\mathrm{CH}_{3}$ and $\mathrm{CH}_{2}$ bending.

Average normal bone spectrum are dominated by two absorbance bands at 1659 and $1537 \mathrm{~cm}^{-1}$ known as the amide I and II, respectively. Amide I arises from $\mathrm{C}-\mathrm{O}$ hydrogen bonded stretching vibrations and amide II from $\mathrm{C}-\mathrm{N}$ stretching and $\mathrm{CNH}$ bending vibrations. The spectral characteristics of both bands are known to be sensitive to protein backbone conformation [13]. The weak band at $1745 \mathrm{~cm}^{-1}$ arises from the stretching mode of $\mathrm{C}-\mathrm{O}$ groups of lipids. The band at $1230 \mathrm{~cm}^{-1}$ is due to the asymmetric phosphate stretching mode [14]. The relatively weak band at $1162 \mathrm{~cm}^{-1}$ in the normal bone is due to stretching mode of $\mathrm{C}-\mathrm{O}$ groups of proteins. The region between 1000 and $1340 \mathrm{~cm}^{-1}$ is dominated by absorptions from collagen (e.g., at 1030, 1230 and $1336 \mathrm{~cm}^{-1}$ ), arising from C-OH stretching vibrations of collagen carbohydrate moieties, $\mathrm{C}-\mathrm{N}$ stretching vibrations of the collagen backbone and $\mathrm{CH}_{2}$ wagging vibrations of collagen side chains [15]. An intense, broad band from $900-1200 \mathrm{~cm}^{-1}$ is, i.e. phosphate 
ions in hydroxyapatite [16]. A small absorption centered at $875 \mathrm{~cm}^{-1}$ arises from carbonate-substituted hydroxyapatite $[17,18]$. These bands are sensitive to mineral content (i.e. carbonate, phosphate, acid phosphate) and mineral crystallinity.

\subsection{Spectral differences and IR microscopic imaging}

Figure 2A shows the light micrograph of the normal area. Necrotic bone regions are labeled in the visual micrographs (Fig. 2C-D). Average IR spectra of the normal (A) and necrotic (B-D) bones were obtained from the same areas by synchrotron IR microspectroscopy, to provide the basis to generate IR maps (Fig. 3). The various absorption bands of interest are labeled.

Significant differences were found between normal and necrotic bone in the FT-IR spectra. In particular, if one compares both groups, the band at $1537 \mathrm{~cm}^{-1}$ (amide II) shift to higher frequency $\left(\sim 1550 \mathrm{~cm}^{-1}\right)$ in the necrotic bone. The band at $1659 \mathrm{~cm}^{-1}$ is attributable to Amide I of $\alpha$-helical structures. It is possible to see another band in the same figure located around $1550 \mathrm{~cm}^{-1}$, which arises from the Amide II of $\alpha$-helical structures of proteins [13]. The wave number and intensity changes as
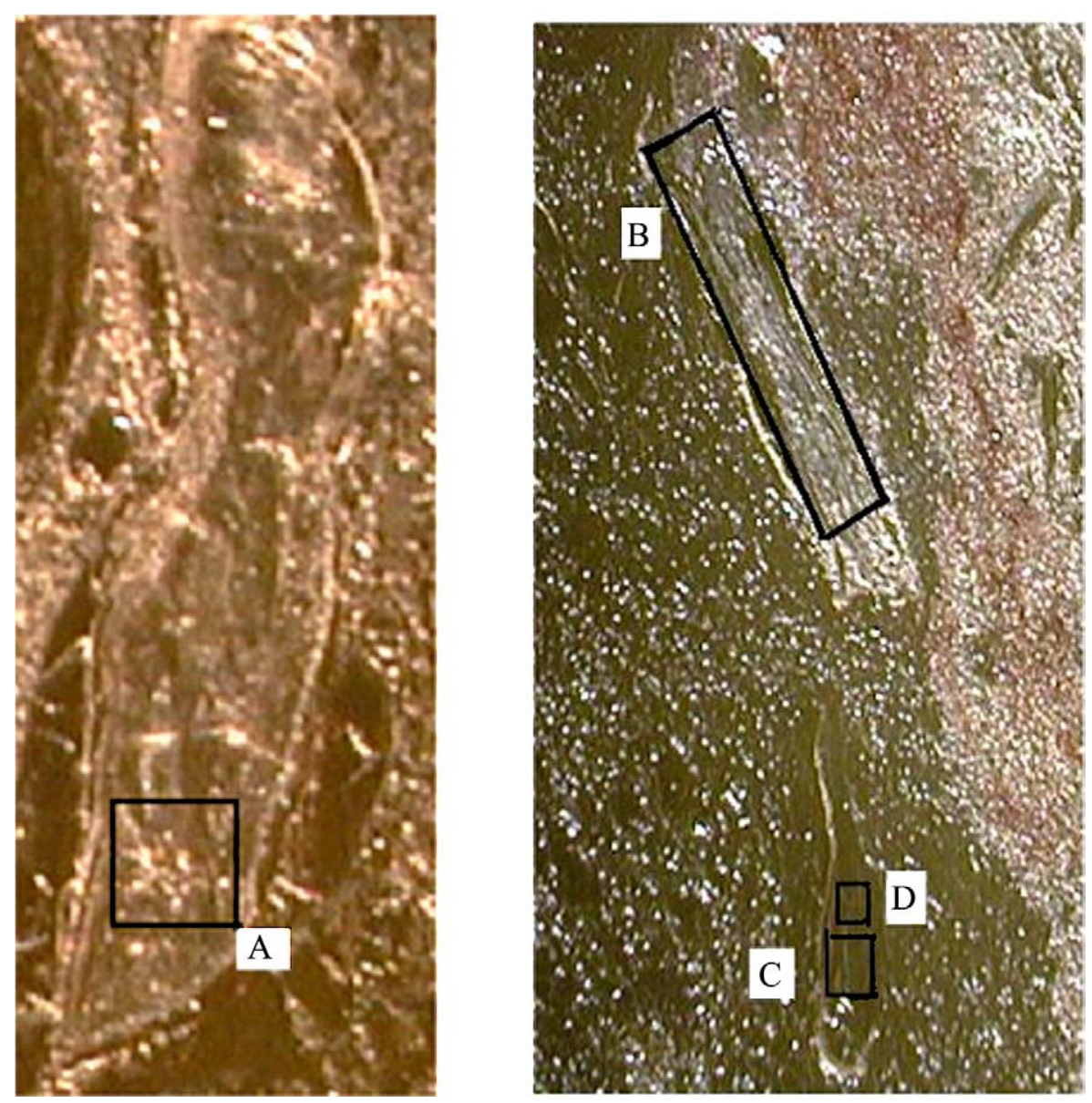

Fig. 2. Photomicrographs of bone sections. The rectangles represent the analysis areas. Normal bone (A), necrotic bones (B-D). The size of each bone area selected; (A) $100 \times 100 \mu \mathrm{m}^{2}$; (B) $100 \times 700 \mu \mathrm{m}^{2}$; (C) $100 \times 100 \mu \mathrm{m}^{2}$ and (D) $50 \times 50 \mu \mathrm{m}^{2}$. 


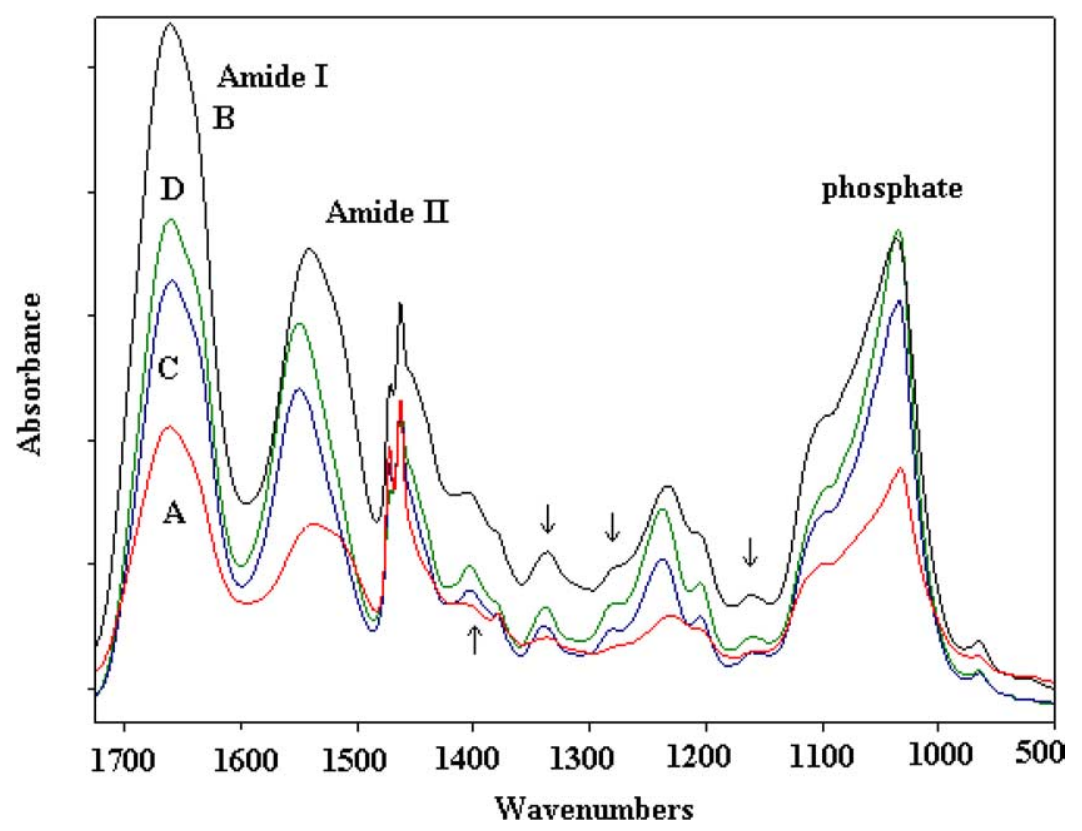

Fig. 3. Average IR spectra obtained from within the square boxes at different areas of the bone sections (normal A and necrotic $\mathrm{B}, \mathrm{C}, \mathrm{D}$ ). The regions of interest are labeled. ( $\rightarrow$ symbol shows the spectral chances between normal and necrotic bones.)

a result of changes in protein secondary structure [19]. The relatively very weak band at $1403 \mathrm{~cm}^{-1}$ in the normal increased in intensity in the necrotic. The collagen bands at 1336 and $1205 \mathrm{~cm}^{-1}$ of normal bone increased in intensity in the necrotic. This might be due to an increase in the content of collagen. The band at $1230 \mathrm{~cm}^{-1}$ due to the asymmetric stretching vibration of $\mathrm{PO}_{2}^{-}$(DNA) of the normal bone increased in intensity in the necrotic and shit to $1238 \mathrm{~cm}^{-1}$. The new band at $1280 \mathrm{~cm}^{-1}$ is observed in the necrotic.

Variation in mineral content in bone is important. Calculation of the ratio of the integrated areas under the $\nu_{1}, \nu_{3}$ phosphate $\left(900-1200 \mathrm{~cm}^{-1}\right)$ and Amide I (1590-1720 $\left.\mathrm{cm}^{-1}\right)$ peaks allowed the determination of the mineral to matrix ratio at each site of micro-FT-IR spectroscopic analysis. The mineral to matrix ratio was shown as directly related to the ash weight of a tissue. Therefore, it is indicative of the relative quantity of mineral present in calcified tissues [20]. Figure 4 shows the variations of mineral to matrix ratio.

The carbonate-to-mineral ratio, an indicator of carbonate content of the mineral phase, was calculated as the ratio of the area of the carbonate $\nu_{2}$ absorbance from 850 to $890 \mathrm{~cm}^{-1}$ to the area of the phosphate $\nu_{1}, \nu_{3}$ phosphate $\left(900-1200 \mathrm{~cm}^{-1}\right)$ absorbance [21]. Figure 5 shows the variations of carbonate to phosphate ratio plotted on the same color scales as Fig. 4.

In humans and in animal models of osteoporosis, diseased bone has a decreased mineral to (organic) matrix ratio, which is characteristic of immature bone [22]. In this study we found that the relative min$\mathrm{eral} / \mathrm{matrix}$ ratio decreased in the necrotic bone. However, carbonate/phosphate ratio (slightly increased) was not significantly different.

Yu et al. [23] have found that the strength and mineral content of necrotic bone decreased in the early phase of avascular necrosis, and with revascularization the bone-mineral content increased. Such 


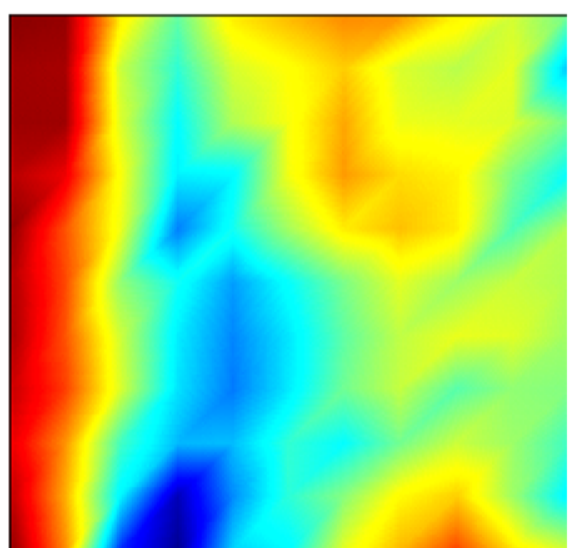

A

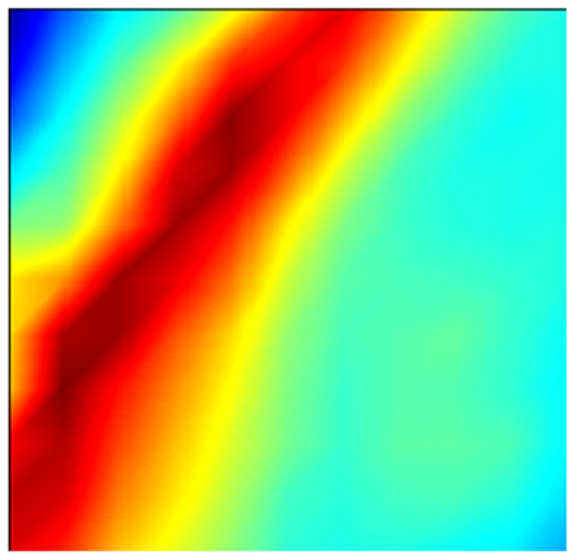

$\mathrm{C}$

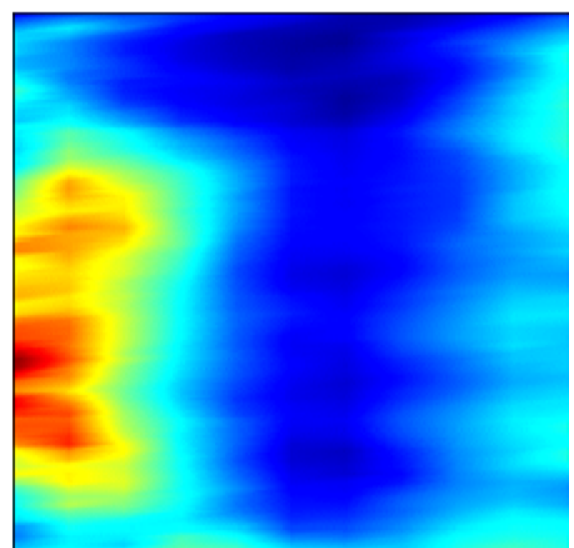

B

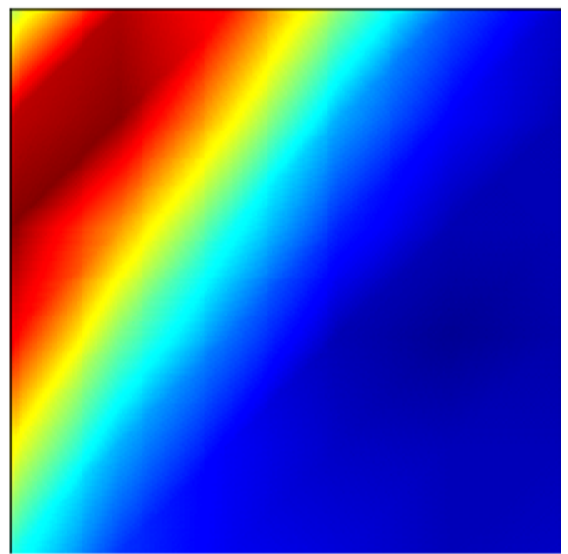

$\mathrm{D}$

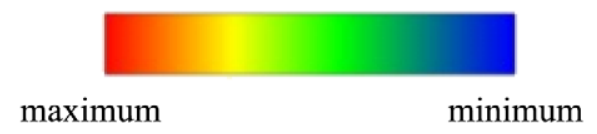

Fig. 4. Mineral to matrix ratio distribution in normal (A) and necrotic bones (B-D). The color coding used to generate the spectroscopic images is identical. Blue is minimum, and red is maximum. (The color reproduction of figures is available from corresponding author or on a WEB site of this journal.)

decrease of bone mineral in necrotic bone may be due to the local metabolic changes. Loroche et al. [24] also reported decreased bone mineral density values at the femoral neck on the normal side for the osteonecrosis patients.

Carbonate accumulation in the bone is also measured by the $\nu_{2}\left(\mathrm{CO}_{3}\right)^{2-}$ to Amide I ratio, which generally increases as bone matures [25]. In this study, carbonate accumulation was reduced. Changes in carbonate metabolism during fracture have general manifestations in bone.

In summary, analysis by FT-IR Microscope in the current study enhanced the understanding of mineralization mechanisms in necrotic bone. In short, FT-IRM brings a new dimension to understanding the composition of bone in avascular necrosis, and has the potential to become a reliable tool for monitoring the disease in situ. 


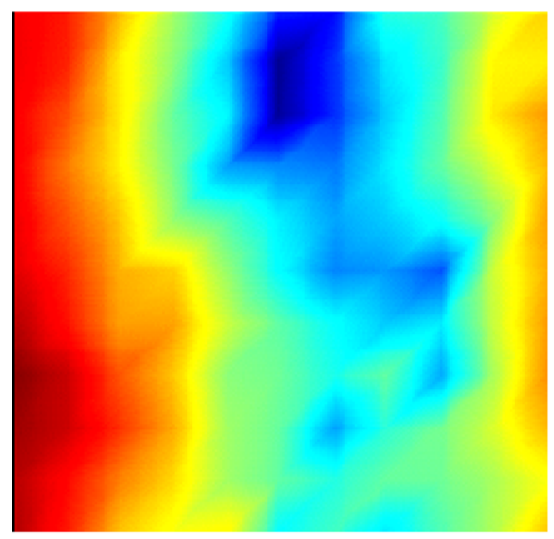

A

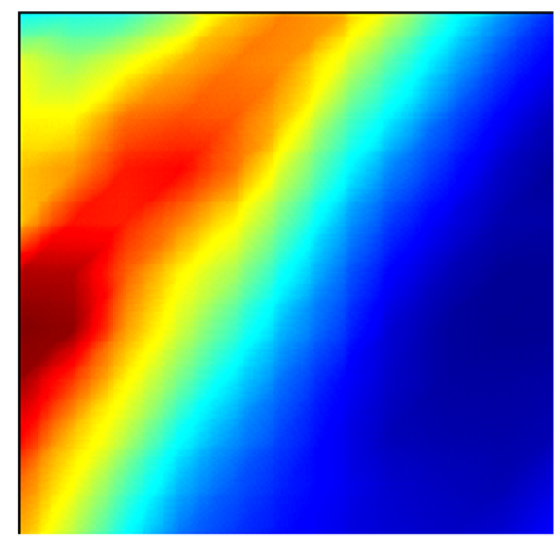

C

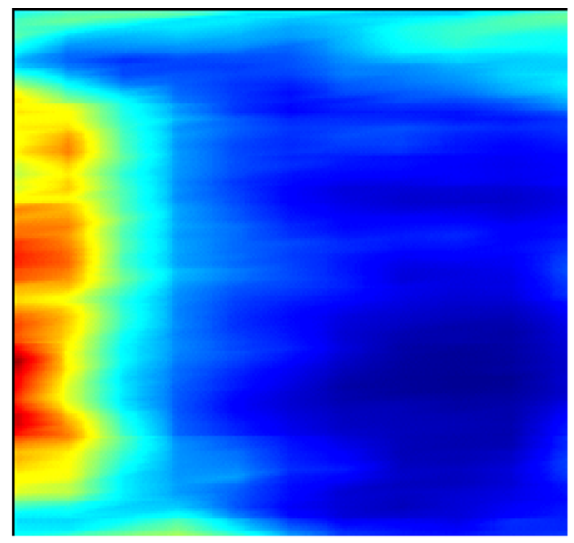

B

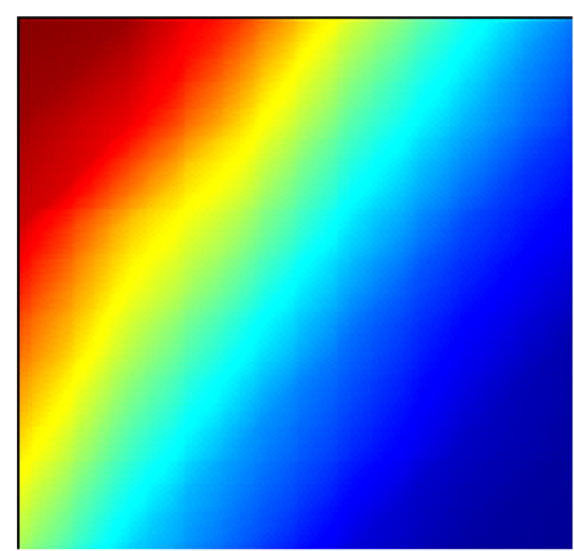

$\mathrm{D}$

Fig. 5. Carbonate to mineral ratio distribution in normal (A) and necrotic bones (B-D). (The color reproduction of figures is available from corresponding author or on a WEB site of this journal.)

\section{Acknowledgements}

We would like to thank SPring-8 BL43IR staff member (T. Moriwaki) for his technical support. We would also like to thank Dr. Beyhan Demirhan for help us to prepare samples. This work was supported by Hacettepe University Research Fund (Grand No. 06D03605001). Experiments were performed with the approval of the Japan Synchrotron Radiation Research Institute Proposal No. 2006B1145 (proposal reference No. 3324). We also thank to Peter Lasch for Cytospec demo program.

\section{References}

[1] P. Lafforgue, Pathophysiology and natural history of avascular necrosis of bone, Joint Bone Spine 73 (2006), 500-507.

[2] H. Boyar, B. Turan and F. Severcan, FTIR spectroscopic investigation of mineral structure of streptozotocin induced diabetic rat femur and tibia, Spectroscopy 17 (2003), 627-633.

[3] R. Mendelsohn, E.P. Paschalis and A.L. Boskey, Infrared spectroscopy, microscopy and microscopic imaging of mineralized tissues: Spectra-structure correlations from human iliac crest biopsies, J. Biomed. Optics 4 (1999), 14-21.

[4] R. Mendelsohn, E.P. Paschalis, P.J. Sherman and A.L. Boskey, IR microscopic imaging of pathological states and fracture healing of bone, Appl. Spectrosc. 54 (2000), 1183-1191. 
[5] R.Y. Huang, L.M. Miller, C.S. Carlson and M.R. Chance, In situ chemistry of osteoporosis revealed by synchrotron infrared microspectroscopy, Bone 33 (2003), 514-521.

[6] H. Boyar, F. Zorlu, M. Mut and F. Severcan, The effects of chronic hypoperfusion on rat cranial bone mineral and organic matrix: A Fourier transform infrared spectroscopy study, Anal. Bioanal. Chem. 379 (2004), 433-438.

[7] L.M. Miller, V. Vairavamurthy, M.R. Chance, R. Mendelsohn, E.P. Paschalis, F. Betts and A.L. Boskey, In situ analysis of mineral content and crystallinity in bone using infrared micro-spectroscopy of the $\nu_{4} \mathrm{PO}_{3}$ vibration, Biochim. Biophys. Acta 1527 (2001), 11-19.

[8] D. Faibish, A. Gomes, G. Boivin, I. Binderman and A.L. Boskey, Infrared imaging of calcified tissue in bone biopsies from adults with osteomalacia, Bone 36 (2005), 6-12.

[9] A.L. Boskey, M. Goldberg, A. Kulkarni and S. Gome, Infrared imaging microscopy of bone: Illustrations from a mouse model of Fabry disease, Biochim. Biophys. Acta 1758(7) (2006), 942-947.

[10] P. Dumas and M.J. Tobin, A bright source for infrared microspectroscopy: synchrotron radiation spectroscopy, Spectrosc. Eur. 15(6) (2003), 17-23.

[11] N.C. Blumenthal, F. Betts and A.S. Posner, Formation and structure of Ca-deficient hydroxyapatite, Calcif. Tissue Int. 33 (1981), 111-117.

[12] A. Tfayli, O. Piota, A. Durlach, P. Bernard and M. Manfaita, Discriminating nevus and melanoma on paraffin-embedded skin biopsies using FTIR microspectroscopy, Biochim. Biophys. Acta 1724 (2005), 262-269.

[13] H. Susi and D. Byler, Resolution-enhanced Fourier transform infrared spectroscopy of enzymes, Methods Enzymol. 130 (1986), 290-311.

[14] E. Taillandier and F. Liquier, Infrared spectroscopy of DNA, Methods Enzymol. 211 (1992), 307-335.

[15] H. Fabian, M. Jackson, L. Murphy, P.H. Watson, I. Fichtner and H.H. Mantsch, A comparative infrared spectroscopic study of human breast tumors and breast tumor cell xenografts, Biospectroscopy 1 (1995), 37-45.

[16] N. Pleshko, A.L. Boskey and R. Mendelsohn, Novel infrared spectroscopic method for the determination of crystallinity of hydroxyapatite minerals, Biophys. J. 60 (1991), 786-793.

[17] C. Rey, M. Shimizu, B. Collins and M.J. Glimcher, Resolution enhanced Fourier transform infrared spectroscopy study of the environment of phosphate ions in the early deposits of a solid phase calcium phosphate in bone and enamel, and their evolution with age: 2. Investigations in the $\nu_{3} \mathrm{PO}_{4}$ domain, Calcified Tissue Int. 49 (1991), 383-388.

[18] R.Y. Huang, L.M. Miller, C.S. Carlson and M.R. Chance, Characterization of bone mineral composition in the proximal tibia of cynomolgus monkeys: effect of ovariectomy and nandrolone decanoate treatment, Bone 30 (2002), 492-497.

[19] M. Jackson and H.H. Mantsch, The use and misuse of FTIR spectroscopy in the determination of protein structure, Crit. Rev. Biochem. Mol. Biol. 30 (1995), 95-120.

[20] N.P. Camacho, S. Rinnerthaler, E.P. Paschalis, R. Mendelsohn, A.L. Boskey and P. Fratzl, Complementary information on bone ultrastructure from scanning small angle X-ray scattering and Fourier-transform infrared microspectroscopy, Bone 25 (1999), 287-293.

[21] S.J. Gadaleta, E.P. Paschalis, F. Betts and R. Mendelsohn, Fourier transform infrared spectroscopy of the solution mediated conversion of amorphous calcium phosphate to hydroxyapatite: new correlations between X-ray diffraction to infrared data, Calcified Tissue Int. 58 (1996), 9-16.

[22] E.P. Paschalis, F. Betts, E. DiCarlo, R. Mendelsohn and A.L. Boskey, FTIR microspectroscopic analysis of human iliac crest biopsies from untreated osteoporotic bone, Calcified Tissue Int. 61 (1997), 487-492.

[23] W.Y. Yu, C.M. Siu, S.S. Shim, H.M. Hawthorne and J.S. Dunbar, Mechanical properties and mineral content of avascular and revascularizing cortical bone, J. Bone Joint Surg. Am. 57 (1975), 692-695.

[24] M. Laroche, L. Costa, J. Bernard, J. Puget, A. Constantin, A. Cantagrel and B. Mazieres, Dual-energy X-ray absorptiometry in osteonecrosis of the femoral head, Rev. Rhum Engl. Ed. 65(6) (1998), 393-396.

[25] S. Bohic, C. Rey, A. Legrand, H. Sfihi, R. Rohanizadeh, C. Martel, A. Barbier and G. Daculsi, Characterization of trabecular rat bone mineral: effect of ovariectomy and bisphosphonate treatment, Bone 26 (2000), 341-348. 


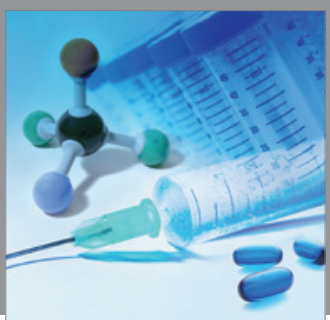

International Journal of

Medicinal Chemistry

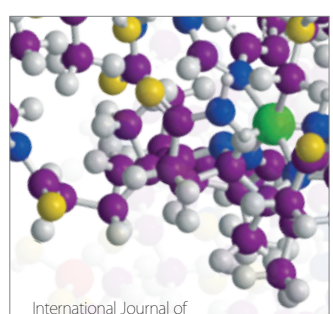

Carbohydrate Chemistry

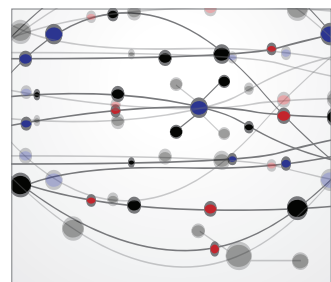

The Scientific World Journal
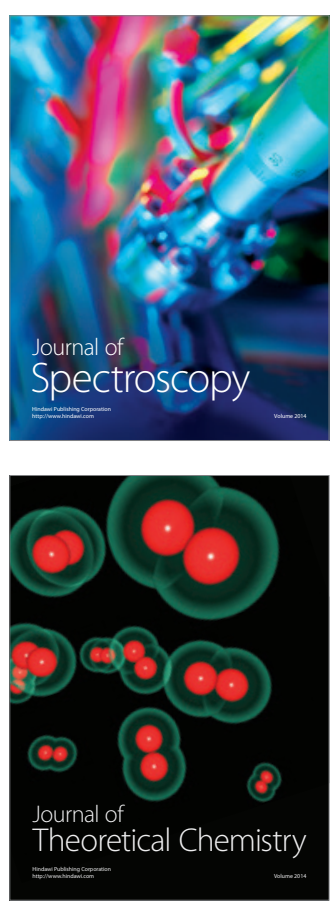
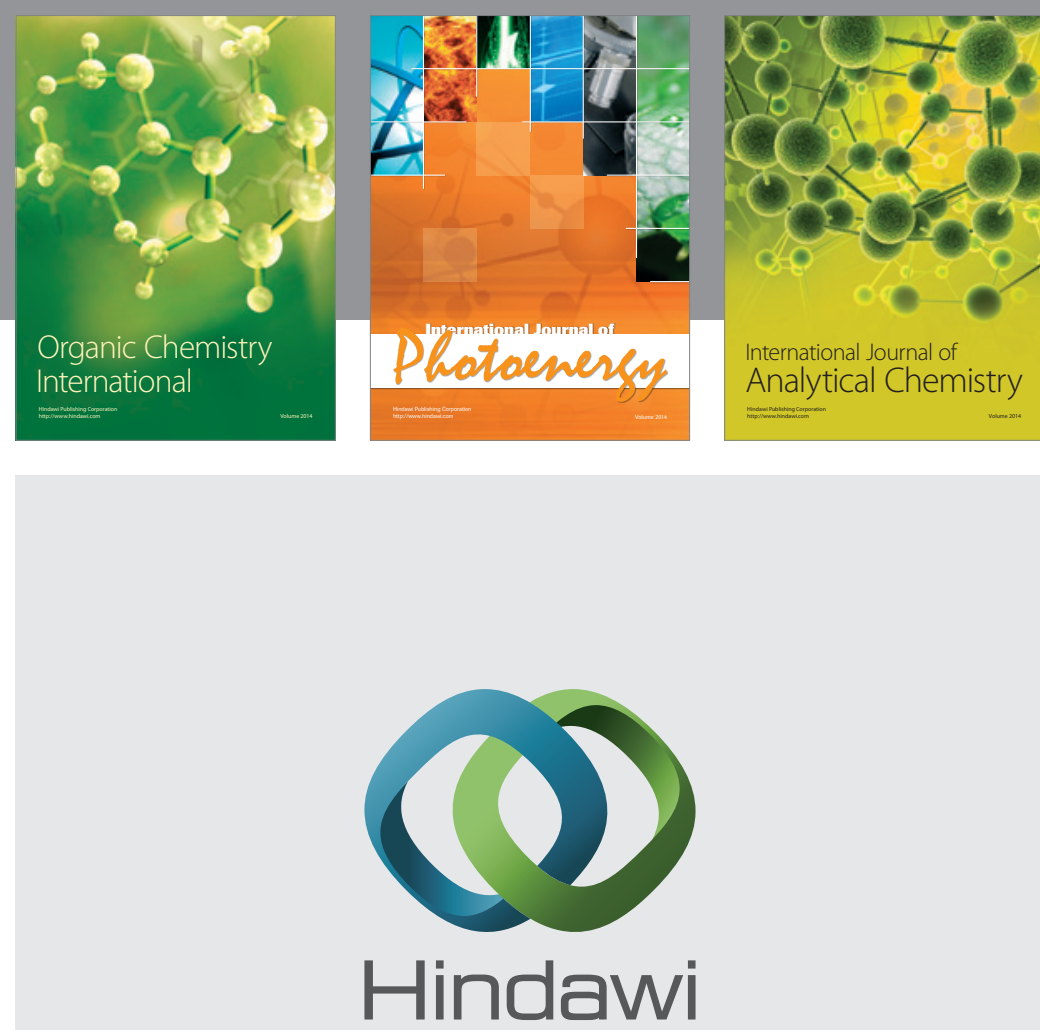

Submit your manuscripts at

http://www.hindawi.com
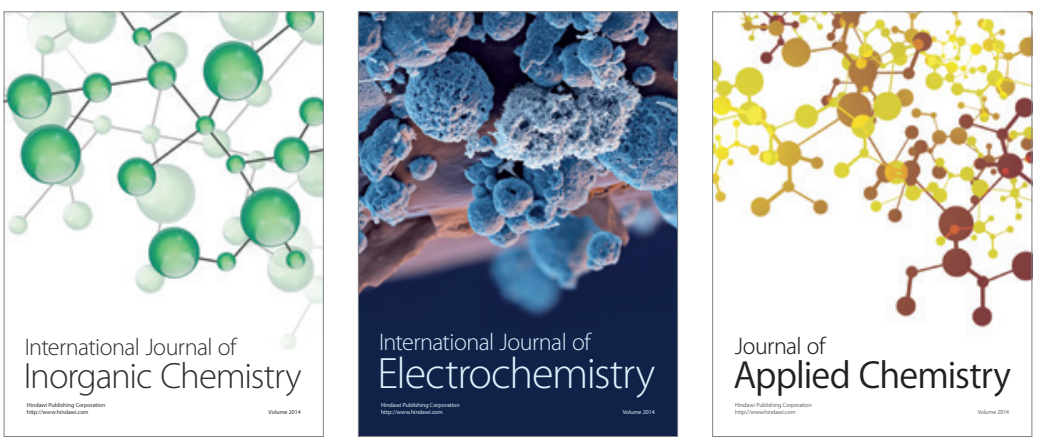

Journal of

Applied Chemistry
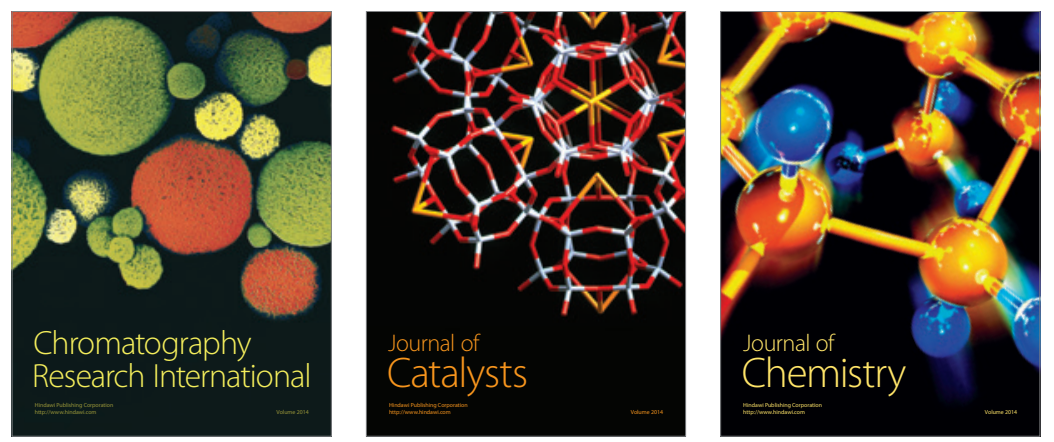
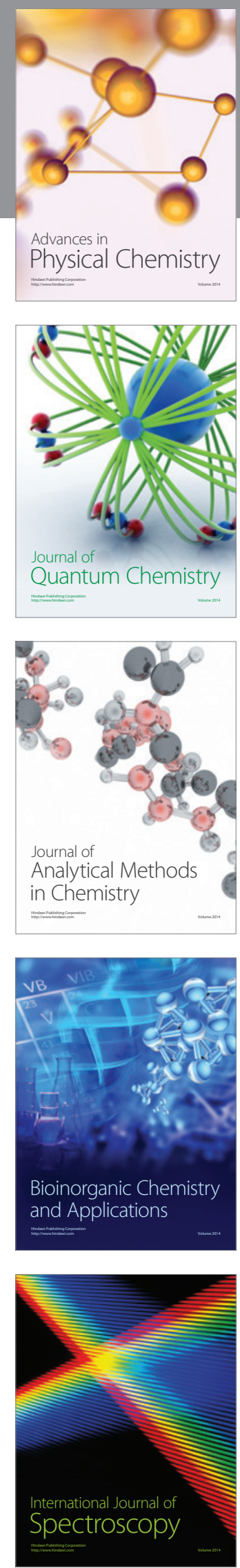